\title{
Correction to: Methodological aspects of superiority, equivalence, and non-inferiority trials
}

\author{
Stefanos Roumeliotis ${ }^{1,2}$ (1) $\cdot$ Graziella D'Arrigo ${ }^{2}$ (i) $\cdot$ Giovanni Tripepi ${ }^{2}$ (1)
}

Published online: 22 September 2020

(c) Società Italiana di Medicina Interna (SIMI) 2020

\section{Correction to: Internal and Emergency Medicine https://doi.org/10.1007/s11739-020-02450-9}

In the original publication of the article, the given name and family name of the author were swapped. The correct author name is given in this erratum.

Publisher's Note Springer Nature remains neutral with regard to jurisdictional claims in published maps and institutional affiliations.

The original article can be found online at https://doi.org/10.1007/ s11739-020-02450-9.

Stefanos Roumeliotis

st_roumeliotis@Hotmail.com

1 Division of Nephrology and Hypertension, 1st Department of Internal Medicine, School of Medicine, AHEPA Hospital, Aristotle University of Thessaloniki, St. Kyriakidi 1, 54636 Thessaloniki, Greece

2 Institute of Clinical Physiology (IFC-CNR), Clinical Epidemiology and Physiopathology of Renal Diseases and Hypertension, Ospedali Riuniti, via Vallone Petrara, Reggio Calabria, Italy 